\title{
Adaptive Capability and Path Creation in the Post-industrial City: The Case of Nottingham's Biotechnology Sector
}

David J. Smith, Will Rossiter and Daniel McDonald-Junor

Nottingham Trent University, 50 Shakespeare Street, Nottingham, NG1 4QF, UK

david.smith02@ntu.ac.uk, william.rossiter@ntu.ac.uk, daniel.mcdonald-junor@ntu.ac.uk

\begin{abstract}
Adaptive capability describes the ability to respond to external shocks and take advantage of new opportunities. Central to this is path dependency and the scope for turning historic strengths to new purposes. This paper explores the emergence of a nascent bioscience cluster in Nottingham. A novel analytical device based on Kingdon's multiple streams framework is applied to explore the emergence of a new development path in this city. Local actors used a window of opportunity created by contingencies at the level of industries, firms and place to create a development path mobilizing legacy assets including physical and human capital.
\end{abstract}

\section{Keywords}

Adaptive capability, path creation, re-generation, cities, biotechnology, clusters JEL classifications: L52, O31, R11 


\section{Adaptive Capability and Path Creation in the Post-industrial City: The Case of Nottingham's Biotechnology Sector}

\section{Introduction}

Just how new development paths are created in city-regions especially those that are or have been home to declining industries has been described as one of the most, 'intriguing and challenging questions' (Neffke et al., 2011, 241). Research in this field has begun to identify some of the causal factors, mechanisms (Dawley, 2013), agents (Simmie, 2012) and conditions (Fornahl et al., 2012) involved. However despite this, a recent study (Dawley et al., 2015, 257) noted that, 'more theoretically informed and empirically grounded research' is required in order to provide greater clarity on new path creation.

This study aims to contribute to filling this gap in our knowledge through the application of a modified version of Kingdon's (1995) multiple streams framework (MSF) in order to analyse the path creation phase of Martin's (2010) path dependency model of local industrial evolution (see figure1). This is the phase where according to Martin (2010, 21), 'experimentation and competition among local agents leads to the emergence of a new path'. Through the application of this framework we seek to provide insights into the process by which new paths are created. Like Kingdom's framework our version comprises three streams of activity. However our streams reflect differing scales of activity, starting with markets/industries at the highest level, followed by firms and then institutions. Co-evolution of these streams over time leads to their converging, thereby creating a 'window of opportunity'. It is at this point according to Kingdon $(1995,20)$ that 'policy entrepreneurs' whom he describes as people capable of 'coupling solutions to problems', emerge to put forward potential solutions. We prefer the term enablers but their function is the same, they are local agents (i.e. individual and corporate actors) able to make use of this window in order to effect change. In this instance the change is the launching of a new industrial development path, one involving the re-tasking of physical assets and the mobilisation of local knowledge and skills accumulated in the city-region over many years.

$* * * * * * * * * * * * * * * * * * * * * * *$

Insert Figure 1

$* * * * * * * * * * * * * * * * * * * * * * * *$ 
We apply this conceptual model to an in-depth case study exploring the emergence of a nascent bioscience based industrial cluster in the city of Nottingham in the UK. The development of BioCity Nottingham, home to a large and growing concentration of biotechnology and healthcare companies, has come to symbolise Nottingham's economic reinvention as a 'knowledge economy' following years of de-industrialisation. From its roots deep in the manufacturing dominated local economy that spawned 'Saturday Night and Sunday Morning', we chart the rise of exactly the kind of knowledge intensive industrial cluster that has been an object of desire for national, regional and local policy makers since the Millennium and before (Swords, 2013). Interesting though the BioCity incubator's emergence is in its own right, the principal focus of this paper is on what this case can tell us about the continuing evolution of Nottingham's economy and the implications that this may have for our understanding of regional economic path creation and adaptive capability more generally.

The local economy of Nottingham faced major structural changes in the late 1990s as manufacturing employment contracted and the balance of the local economy shifted towards services. The case places particular emphasis on the contribution of firms, the restructuring of industry sectors and institutional changes that occurred at this time, to the city's adaptive capability. In the process the case study reveals a notable example of adaptation as the local economy moved away from a previous path of regional and sectoral development, towards a new and yet related trajectory. Central to this process was the purposive re-tasking of physical assets and the mobilization of knowledge assets that were the legacy of one of the city's historic industrial strengths.

The city's industrial past provided a potential escape route from 'negative lock-in' (Amison and Bailey, 2015, 397) for a city on a declining development path caused by a steady process of de-industrialisation since the 1970s. Nottingham's emerging bioscience cluster may be an example of what Christopherson $(2009,277)$ terms, 'phoenix industries'. Not only has a new industrial sector arisen out of an old one, a small number of dominant large employers have been replaced by many small and medium sized companies. The case study provides a valuable insight into the messy and unpredictable process that local agents have to navigate, offering a glimpse of why some localities may be more successful in enabling this process than others. 
The paper concludes by considering the wider relevance and applicability of this model of bioscience based regional development. In so doing it endeavours to isolate those factors that are 'place specific' from those that have wider applicability.

\section{Selective Literature Review}

Evolutionary accounts of regional and local economic development are not new. Alfred Marshall (1920) originated the concept of the industrial district and sought to explain the emergence industrial clusters with reference to a range of factors such as proximity to natural resources and markets for goods and labour. More recently, Nelson and Winter's (1982) seminal work on evolutionary economics explored the role of economic actors and paths of change in the context of time and space. Recent years have seen a marked resurgence of interest in evolutionary accounts of regional and local economic development - often associated with the New Economic Geography or the 'evolutionary turn in economic geography' (see for example Boschma, 2004, Martin and Sunley, 2006). Central to these perspectives on economic development are the related concepts of path dependency, lock-in and adaptive capability.

Path dependency is a term that finds application in both economic geography and institutional perspectives in political science. It highlights the manner in which a region's future paths of development are constrained by the products of social and economic history: accumulations of capital (human and physical), concentrations of expertise, productive infrastructure, institutional architecture etc. There remains scope for agency, but it is constrained by the products of history and the resources that represent a legacy of prior development.

Closely associated with the concept of path dependency is the idea of lock-in - the manner in which a locality or region gets trapped on a path of relative or absolute decline. Often this is associated with the demise of a key local industry. Prior to the millennium, Nottingham bore all the hallmarks of a city region trapped on just such a trajectory. Martin and Sunley (2006, 430) note that,

"place dependence is an important dimension of path dependence. This implies that forms of co-evolution in which there are mutually constitutive interactions and feedbacks between firms and other institutions are to some degree place-specific, and that these interactions occur simultaneously across several different scales."

The literature devotes far less attention to the means through which lock-in may be avoided. From a policy perspective, this is perhaps the critical question. One response to this has been 
to focus on the factors that influence a region's adaptive capability (Martin 2005). Adaptive capability refers to the ability of a region to respond to shocks and take advantage of new development opportunities from wherever they appear. Central to this attribute is the ability to apply historic accumulations of assets or capabilities to new and emerging opportunities as and when they arise.

More recently there has been widespread recognition of the need to engage more fully with the process of path creation (Martin and Sunley 2006). This was a theme to which Martin returned in his Roepke Lecture of 2010, providing a critique of the path dependency model and the central concept of lock-in as privileging continuity over change (Martin, 2010). This may be seen as a reaction against the perceived historical determinism implied by many formulations of path dependency. Martin's response was to argue for a more evolutionary account - applying institutionalist insights from political science to the study of economic geography.

Recent papers by Doussard and Schrock (2015) and Dawley et al (2015) and Bristow and Healy (2015) respond to this challenge. The former's study of North American manufacturing highlights the importance of firm, technological, place and market level contingencies structuring uneven spatial development. In contrast, Dawley at al (2015) identify regional policy initiatives and the multi-scalar state as fulfilling mediating functions in the creation of new paths of development. Bristow and Healy (2015) in turn explore the nature and scope of agency in regional development. Arguably the key insight that they derive is a recognition of the importance of interaction between actors and the sense in which "agents are co-evolving, constantly adapting to each other and to their environment" (Bristow and Healy 2015, 246).

This paper engages with the process of path creation - with a particular emphasis on the interaction between institutions, agents and place over time. We seek to identify the sources of a city region's adaptive capability in the co-evolution of institutions, firms and markets. A simplified model of path creation is used that takes inspiration from the multiple streams framework (MSF) of John Kingdon (1995). MSF is a perspective on the policy process as comprising three parallel streams of activity: problems, policy and politics. Convergence provide 'windows of opportunity' to effect changes of policy direction. The agency of particular 'policy entrepreneurs' is seen to be critical if opportunities are to be realised.

The appeal of MSF as a model of the policy process is that it eschews simplistic linear or cyclical representations of the process (Rossiter and Price 2013). The strength of this approach is its ability to disentangle the often messy process that is the 'real world' of policy. A world 
in which parallel streams of activity happen simultaneously, sometimes independent of each other, sometimes interacting. These characteristics make the MSF account of policy change an interesting and relevant analogue for similar processes at work in regional and local economic path creation. Central is a recognition of the importance of agency if policy outcomes are to be understood. Following Dawley et al (2015) and Bristow and Healy (2015) we see agency associated with the local implementation of regional policy as an important ingredient in the local 'recipe' that led to the creation of Nottingham's growing biotechnology sector.

\section{Methodology}

In developing a case study of the development of the local economy in Nottingham, multiple sources of data were employed. Extensive use was made of documentary and archival materials. The documentary materials included a variety of items from weekly and monthly trade magazines and periodicals, as well as the local and financial press. A number of business histories, industry studies and even biographies and autobiographies were also used to provide background data on the local economy and the development of the pharmaceutical industry in the region. Overall these sources provided a wealth of valuable background and technical information in relation to the pharmaceutical industry in Nottingham. The study also drew on previous research carried out by the authors exploring the nature of the BioCity incubator and analysing its growth and development, as well as other studies of the biotechnology incubator sector in the UK. The data gathered in this way was complemented by a small number of interviews with 'key informants' (John and Reve, 1982), including staff employed at the facility prior to its closure as an industrial research laboratory, at some of the agencies involved in negotiating and organising the transition to an incubator and at the incubator itself. Data from the interviews was extremely helpful in understanding and making sense of some of technical aspects surrounding the activities undertaken at the laboratory facility and the key issues that arose in facilitating the transition.

\section{Case Study: A new development path emerges in Nottingham}

\section{Adaptive capability and the development of Nottingham's economy}

Nottingham has long been a centre of governmental, commercial and cultural life (Heath, 2010). The establishment of the hosiery industry at the start of the eighteenth century saw the town emerge as a major centre of manufacturing industry (Henstock, Dunster \& Wallwork, 
2006). The physical legacy of this industrial heritage is still apparent in the Lace Market area today.

New industries like cycle manufacture, tobacco and pharmaceuticals, took root in the late nineteenth and early twentieth centuries. Although in one case, that of the cycle maker Raleigh, founded by two textile machinery makers and a lace worker (Rosen, 2002), this was the product of a process of industrial adaptation that was to re-occur as the local economy evolved. Boots began the development of the city's industrial science base when the outbreak of war with Germany in 1914 brought crippling shortages of synthetic pharmaceuticals (Corley, 2003). Jesse Boot launched a range of pharmaceutical products extending from aspirin to anaesthetics (Corley, 2003).

The interwar years were marked by further adaptation as hosiery and knitwear (Chapman, 2002) largely replaced lace (Wells, 1966). New industries (Wells, 1966), continued to expand and grow, as the economic environment of the interwar years favoured branded consumer goods for the home market (Pollard,1992). Boots continued to expand pharmaceutical manufacture. The company had the third highest level of patent filings for a UK-owned pharmaceutical company (Slinn, 2008) by the late 1930s. Overall the period saw a significant re-shaping and diversification of employment in the city (Wells, 1966).

By the 1960s Boots, Raleigh and Players had become mainstays of the local economy (Chapman, 2006), with each employing almost 10,000 in the city. Boots had developed into one of the UK's leading pharmaceutical companies, having invested heavily in new research facilities. Among its major achievements was the discovery of the widely used pain-killer ibuprofen. However Nottingham reached its zenith as an industrial city in the 1960s (Heath, 2010). Increased car ownership combined with stiffer overseas competition saw Raleigh's output and employment steadily decline (Chapman, 2006). Likewise Players, now part of Imperial Tobacco, was subject to a similar pattern of declining employment during the course of the 1970s and 1980s, in the face of increasing public recognition of the health risks associated with tobacco and cigarette smoking.

$* * * * * * * * * * * *$

Insert Table 1

$* * * * * * * * * * * * *$ 
While Raleigh and Players went into decline from the 1970s Boots continued to prosper. It acquired Crookes Laboratories and Rucker Pharmacol, and in the 1980s the Flint division of Baxter Tavernol (Chapman, 2006) - an American concern whose drug synthroid, was a big selling treatment for thyroid conditions. Boots was the UK's fifth largest pharmaceutical manufacturer by the mid-1980s (see table 1), but lacked the international marketing capability of larger rivals.

By the early 2000s both Raleigh and Players had ceased manufacturing operations and manufacturing employment in city continued to contract. This decline was matched by the growth of service sector employment. This transformation has seen particular growth in the business/information services with several large companies now based in Nottingham including Experian, Capital One and Ikano. Experian is much the largest with more than 2000 employees in the city (Lawton et al., 2014, Nottingham Post, 2013). Unlike the other two which are the result of inward investment, Experian originated in Nottingham, having begun life in the 1970s as the credit checking arm of Great Universal Stores (Nottingham Post 2013). Thus the overall trajectory that has led Nottingham to become dominated by the service sector, reflects an interesting mix of capabilities that are the product of successive evolutions of firms and industries. In this respect Nottingham differs markedly from near neighbour Derby. The recent development trajectories of Nottingham and Derby have been contrasted in the following terms:

“...over recent decades Derby and Nottingham have assumed quite different roles in the space-economy of the Region. The former can be characterised as the regional centre for manufacturing (with a particular emphasis on transport), while the latter has assumed the role of the regional centre for business, financial, health and education services" (Rossiter 2016; 842)

Viewing the East Midlands region from a wider spatial perspective, Coombes et al. (2005) highlight the 'pre-eminence' of Nottingham as a regional centre, while hesitating to ascribe to it the dominance characteristic of cities like Birmingham and Manchester in the West Midlands and North West respectively. The continuing significance of the cities of Derby and Leicester in the space-economy of the region they attribute to the distinctive pattern of industrialisation in the East Midlands. A pattern that saw each of the five historic county towns grow without 
any one totally subsuming or dominating the others in the manner seen in some English regions (Beckett, 1988, Coombes et al., 2005).

\section{A new development path}

In the last couple of decades a new development path, has emerged in Nottingham. Based on bioscience and health, the most obvious symbol of this new development path is the bioscience cluster centred on the BioCity incubator and comprising more than 60 bioscience related companies established in Nottingham since 2000. Other symbols include Nottingham's designation by the UK government in 2005 as one of six 'Science Cities' (Charles and Wray, 2015), and the East Midlands Development Agency (EMDA)'s selection in its Regional Economic Strategy, entitled 'A flourishing region' (EMDA, 2006), of bioscience/health as one of four priority sectors predicted to, 'make the greatest contribution to the East Midlands economy over the lifetime of the strategy'. Similarly the Nottingham Growth Plan (Nottingham City Council, 2012), explicitly recognized recent changes in the city's economy by identifying biosciences as a 'growth sector' in which the city had a 'competitive advantage'.

Although modest in scale by the standards of bioscience concentrations in the traditional heartlands of London and the South East (Smith and Ehret, 2013), the emergence of bioscience in Nottingham is significant for a non-core region. This momentum has been sustained over a 15 year timeframe and shows no signs of slowing. How has this come about? It is tempting to suggest that it is simply a matter of serendipity - a product of a series of chance events such as BASF's decision to sell its pharmaceutical division to Abbott Laboratories in 2000 and the gifting of the Nottingham site to Nottingham Trent University (NTU). This would be simplistic and ignores strong elements of path dependency revealed when we consider the wider economic and institutional context.

\section{The Multiple Streams Framework}

Using the modified version of Kingdon's (1995) MSF there appear in this case to be three parallel yet inter-acting and co-evolving streams of development (see figure 2). These came together to create a 'window of opportunity' for Nottingham at the beginning of the twentyfirst century. These streams also interacted to provide the capability necessary to take advantage of an opportunity that they were implicated in creating.

$* * * * * * * * * * * * * * *$ 
Insert Figure 2

$* * * * * * * * * * * * * * *$

\section{The market/industry stream}

The first stream of activity operates at the market/industry level. The 1990s were a tumultuous decade for the worldwide pharmaceutical industry, with a succession of high profile mergers (see table 2), including several of which were cross border ones. This brought significant restructuring of the industry (Owen, 1999) as consolidation led to the emergence of a small number of pharmaceutical giants.

Underlying this process were a number of factors. Foremost was the rising cost of drug development, with leading firms spending 15-18 per cent of their turnover on research and development (R \& D), and a new drug taking at least 10 years to develop at a cost of $\$ 250$ $\$ 350$ to develop (Collett, 2000). Consequently a major driving force for increased consolidation in the industry was to economize on R \& D (Jones, 2000).

$* * * * * * * * * * * * *$

Insert Table 2

$* * * * * * * * * * * * *$

Changes occurred in the model of R \& D used by many pharmaceutical companies. There was a gradual move away from 'the traditional paradigm of R \& D' (Chesborough, 2006) associated with closed models of innovation found in vertically integrated firms. With greater emphasis on biotechnology (Pisano, 2006), the use of combinatorial chemistry and microassays, pharmaceutical companies, in a manner similar to firms in other high tech sectors, such as computer firms in Silicon Valley ${ }^{2}$ (Saxenian, 1996), were able to utilize outsourcing. Through outsourcing they came increasingly to rely on external R \& D. Between 1993 and 1998 external $\mathrm{R} \& \mathrm{D}$ undertaken by pharmaceutical firms in the UK more than doubled to $£ 555 \mathrm{~m}$ (Jones, 2000: 349). Third party organisations became the source of a range of research services and even new drugs. Across the UK the number of small specialist biotechnology companies doubled between 1994 and 1999 (DTI, 1999). The shift away from a 'closed' model of innovation in favour of more 'open' models created a market opportunity for exactly the kinds of biotech firms that would later come to occupy BioCity, as did the emergence and adoption 
during the 1990s of the 'triple helix' model (Etzkowitz, 1993) of university-industrygovernment collaboration.

\section{The firm stream}

The second stream operates at the firm level and in this case centred on Boots and its pharmaceutical division. This stream is influenced to a significant extent by the industry/market developments described above in that Boots was responding to the changing nature of its competitive environment and the wider restructuring that was happening throughout the sector. By the 1990s Boots had a potentially valuable drug development pipeline. Its most notable success had been the discovery of the painkiller ibuprofen, but there were others including synthroid and sibutramine, though the company's lack of international marketing skills, meant none quite realised their full potential as a blockbuster drug. Then a combination of regulatory problems, together with leadership changes that brought in a strong retail focus resulting in a series of costly acquisitions (these included the Halfords automotive parts chain, and the Payless and FADS home improvement chains), began to call the future of the company's pharmaceutical division into question.

As part of the company's new focus the over-the-counter (OTC) and contract manufacturing units were split off. Boots Pharmaceuticals retained responsibility for prescription only drugs. This was the point at which the company's drug pipeline hit problems. In 1992, having spent 14 years and $£ 150$ million on research and development (Hoskings, 1993), Boots was finally granted a licence in the UK for its new heart drug manoplax (see table 3). Back in 1979 biochemists at Boots laboratories in Nottingham first synthesized flosequinan, the active ingredient in manoplax, and it came to be seen as the, "great white hope not only for Boots Pharmaceuticals, but for the wider group" (Hoskings, 1993). Within a year, Boots was forced to withdraw manoplax, as a result of regulatory concerns linked to new research which showed that while it was effective in relieving the symptoms of congestive heart failure (CHF) it could shorten life slightly (Rossiter and Smith, 2017).

$* * * * * * * * * * * * *$

Insert Table 3

$* * * * * * * * * * * * * *$ 
With its ambitious plans for expansion into new areas of retailing having failed and its drug development pipeline in tatters, Boots took the decision to divest itself of the prescription only drug business. Early in 1995 it was sold to the German chemical conglomerate BASF for $£ 850$ million (Green, 1994). Although this ended Boots involvement in the prescription drugs sector the company retained the over-the-counter pharmaceutical business along with contract manufacturing.

Part of the attraction for BASF was that it already had a pharmaceutical business which traded under the Knoll brand and a worldwide marketing network. Also Boots had an anti-obesity drug, "at a fairly advanced stage" (Hoskings, 1993), and this held the promise of large sales in the US where BASF already had a significant presence. Despite these attractions BASF's ownership of the Boots research laboratories in Nottingham was to prove relatively short-lived.

Within four years, BASF too was conducting a strategic review. The pharmaceutical division was still relatively small comprising just one tenth of overall group turnover (Abelhauser et al., 2004) and many found it difficult to see BASF as anything other than a chemical company. This was compounded by regulatory concerns limiting the use of reductil the anti-obesity drug developed by Boots (Rossiter and Smith, 2017). With a wave of mergers driving many pharmaceutical companies to seek further acquisitions, BASF took the decision to divest. In March 2001, following approval from the European and US competition authorities, Abbott Laboratories of Illinois acquired the worldwide business of Knoll Pharmaceuticals for \$6.9 billion (Abelhauser et al., 2004). This time the purchaser wanted the intellectual property but not the Nottingham site or its staff. Consequently BASF was forced to make 450 highly qualified scientific staff redundant. The redundancies coincided with the closure of the last Raleigh manufacturing plant in Nottingham and another big manufacturing plant in the city, Royal Ordnance owned by British Aerospace.

\section{The institutional stream}

The third stream comprises the development of local institutions, including both scientific and administrative organisations. This was to prove critical in developing the adaptive capability necessary to take advantage of a window of opportunity when it arose. There is a strong sense in which these institution were themselves a product of a particular industrial milieu and the constellation of local firms within which Boots was a prominent member. Chief among these public sector anchor institutions to develop was the Queens Medical Centre (QMC) opened in 
1977 following the creation of a new Medical School at the University of Nottingham in 1970. The QMC was the first purpose-built teaching hospital to be constructed in the UK, and is now one of the largest teaching hospitals in England (Mathieson, 2011). Currently the main acute hospital for the East Midlands region QMC employs nearly 12,000 staff. As such it constitutes a significant addition to the City's science base, helping to generate 'critical mass' in health related biosciences (Rossiter and Smith, 2017). It thus fulfils a dual role: boosting the local science-based labour market in and stimulating demand for health related bioscience services and expertise.

Other important public sector anchor institutions that form part of the city's science base included its two universities. From their earliest years both had close contact with local industry. Nottingham's University College finally gained its charter to become a full university in 1948 having acquired a large new 300 acre campus two miles south west of the city in the interwar years, through the generosity of Boots founder (Chapman, 1974). From this point onwards Nottingham University developed into one of the UK's leading research intensive universities, with major departments in bioscience and healthcare and rated a, 'leading biotechnology research university' in terms of funding support from the relevant UK research councils. A measure of the university's rise among the scientific community was its first Nobel prize in 2003 awarded to Sir Peter Mansfield for his work on Magnetic Resonance Imaging (Ehret et al., 2012). The city's polytechnic meanwhile, which had for a long time played an important role in training technicians and laboratory staff working in local companies like Boots, merged with the city's college of education in 1975. It gained independence from local authority control following the 1988 Education Act, before achieving university status in 1992 when it became Nottingham Trent University (NTU).

The development of Nottingham's two universities and their relation to local industry is itself noteworthy and provides further evidence of co-evolution. Indeed, in different ways the development of both universities may be seen as directly stimulated by local industry. The philanthropy of Jesse Boot played a key role in the development of the University of Nottingham, just as the needs of local manufacturing firms had stimulated the creation of NTU's earliest antecedent - the College of Design - in the 1840s. To this extent both universities can be regarded as products of a particular industrial milieu. 
Other important institutional developments locally included the award of unitary status to Nottingham City Council in 1998. The significance of this was to increase the authority's influence over and resources devoted to strategic planning, transport and economic development in the city. The following year saw another important institutional development, the establishment of regional development agencies (RDAs) across the UK, as part of New Labour's new focus on regional policy ${ }^{3}$. This included the East Midlands Development Agency (EMDA) based in Nottingham. EMDA was a key part of the actor network associated with attempts to implement the government's cluster policies derived from the work of Michael Porter, that were very much in vogue at this time (Swords, 2013). EMDA was also an important actor in economic development at the local level. This derived both from its statutory remit and the funds at its disposal. By accident of location, it is noteworthy that EMDA's main offices in Nottingham overlooked the Pennyfoot Street laboratory site - meaning that the site and its potential future use could hardly fail to be prominent in the minds of key EMDA staff.

\section{A Window of Opportunity}

The convergence of these three streams in the late 1990s served to create both a major economic challenge and a means to respond. In the industry stream, firm consolidation combined with increased use of open innovation and increased commercialisation of university research through the triple helix model, caused many in the pharmaceutical industry to question the value of large centralised research laboratories. In parallel at the firm level, Nottingham saw the departure of two of its big three employers (Raleigh and Players). Then first Boots and then BASF ran into major problems with their drug development pipelines, bringing the future of the city's pharmaceuticals manufacturing and research into question. Meanwhile the institutional stream had seen further development as the incoming Labour administration of 1997 began to implement new regional and cluster policies leading to the creation of a development agency based in Nottingham.

It was the decision by BASF to sell the Knoll Pharmaceuticals business to Abbott Laboratories in 2000 (Abelhauser et al., 2004) in a deal that involved the intellectual property (i.e. the drugs and drug pipelines) but not the Nottingham site and its staff that proved to be a critical juncture. BASF had little choice but to close the facility and make nearly 500 staff redundant. This directed attention to the wider problem of the decline Nottingham's industrial base. Hence the sale to Abbott Laboratories proved to be what Zahariadis $(2007,72)$ terms a 'focusing event', serving to couple the three streams together at a critical moment in time, and creating a 
'window of opportunity'. This created a fertile environment for various actors in Kingdon's (1995, 165) words, "to push their pet solutions".

A number of potential solutions to the problem of what to do with the former Boots research laboratories, were to emerge from a variety of actors able to play the part of Kingdon's (1995, 179) 'policy entrepreneur'. The most obvious solution was for BASF as the principal actor, to find another pharmaceutical manufacturer or a firm working in a similar field, to purchase the facility. But as one former employee noted, "nobody wanted the site when we tried to sell it for its existing purpose - that was clear". Hence despite the company's best efforts it very quickly became apparent that this was not a viable option. A second solution also involved BASF as actor. This involved demolishing the buildings, cleaning up the site and selling it to a developer able to put the site to an alternative use. However this proved not to be a feasible option because much of the land was badly contaminated through earlier industrial activity meaning that, as the source quoted earlier noted,

"it would not be worth anything particularly as its riddled with tributaries of the river Lean underneath, which means building anything on top of it as a property development was also going to be monstrously expensive".

Given this apparent impasse, a third solution to come forward involved a different actor. Given the site's proximity to NTU's city campus in the heart of Nottingham, the possibility of the university taking it over was considered. Talks were held with Ray Cowell, NTU's vicechancellor at this time. A number of visits by university staff to look at the Pennyfoot Street laboratories were undertaken. Having envisaged that they would be able to convert much of the space to lecture theatres and classrooms in order to provide space for teaching, they were disappointed to learn that this would not be possible. Two factors lay behind this. In part BASF wasn't keen on wholesale conversion, but more significant was the fact that to fund the changes NTU would have needed help from EMDA. Wherever possible, EMDA's senior management tried to avoid being seen to favour a single institution where others in the same sector could be disadvantaged. It is also doubtful whether a teaching only use would have been seen as sufficiently close to the agency's strategic priorities to justify funding. As a result this third option was, "pretty soon squashed”. By this stage a fourth possible solution involving another group of actors had emerged. 
When the closure of the site was announced several of BASF's employees, including senior scientific staff, began making plans to establish spin-off businesses utilizing their prior expertise and experience. The furthest advanced were a team of specialists in obesity treatments, who set up a company called RenaSci Ltd, providing "contract screening and expert services". They had been allowed to remain on site and were keen to rent laboratory space. Nor were they the only ones keen to rent space. A Cambridge based company was also very keen to rent specialist chemistry laboratory space. Hence a fourth possible solution to emerge in this window of opportunity was the idea that the redundant research laboratories might be turned into some form of incubator housing small start-up bioscience businesses.

In the event this was the solution that won the day. It led to BASF announcing in August 2001 that it was gifting the laboratories in Nottingham to NTU. Valued at some $£ 4$ million the facility comprised more than 100,000 square feet (THE, 2001) of laboratory space. The laboratories would have cost close to $£ 50$ million to build and equip at then current prices (Hansard, 2008). It was the largest corporate donation ever to have been made to a post-1992 university (Hansard, 2008).

However it required a 'policy entrepreneur' to enable this solution to gain traction. This was the newly formed development agency, EMDA. The agency was in a unique position. Created in 1999, it was very much a 'new kid on the block'. Despite this, or more likely because of it, EMDA was eventually able to broker a deal. Central to this deal was ensuring that the city's two universities, who often found themselves in competition both for students and academic staff, worked together.

EMDA's distinctive contribution to the local recipe was to facilitate the establishment of a collaborative joint venture comprising the two universities and EMDA. The Agency also had a remit from the then Department for Trade and Industry to implement regional cluster policies and to this the Agency could therefore add a level of financial resources commensurate with the task of re-purposing the Pennyfoot Street laboratories.

The result was what has been described as,

"a unique example of strong collaboration between a Regional Development Agency (East Midlands Development Agency), two universities (the Nottingham Trent 
University and the University of Nottingham) and a major science-based company (BASF plc)." (Hansard, 2008).

This collaboration involved the laboratories, though now owned by NTU, being operated by a joint venture involving a three way partnership between NTU, Nottingham University and EMDA. The laboratories were to be used as an incubator housing small start-up firms not only in biotechnology but also in healthcare, including several that employed former BASF/Boots and others founded by staff from both of the local universities. In return BASF agreed to cover the cost of running the facility until the partners had had an opportunity to, "develop a robust business plan and secure the necessary funding" (Hansard, 2008), and the new operating company was ready to take it over.

\section{The BioCity incubator and the development of Nottingham's bioscience cluster}

Thus was borne 'BioCity Nottingham' a bioscience incubator designed to facilitate the biomedical research of universities in the region, especially at the technology-transfer stage. The first phase of the development was opened by the science minister, Lord Sainsbury in September 2003 (Connon, 2003). By 2009 two further phases had been opened (Smith and Ehret, 2013). In 2014 plans were announced for the construction of an entirely new building. Due to open in 2017 this new facility will provide a further 50,000 square feet of laboratory space. This latest addition will consolidate BioCity's position as by far the largest bioscience incubator in the UK (McDonald-Junor 2016).

The mix of tenants reflects that found in other non-core regions. Just over one third of the science-based companies, were utilising a 'product' (i.e. drug discovery) business model, based on what Pisano $(2006,2)$ terms a model designed to, "monetize intellectual property" (IP). In contrast, the other two thirds were using a 'service' business model. With this business model companies are not seeking to commercialise intellectual property but instead were contract research organisations (CROs) focusing on the provision of a range of specialised research services that typically facilitate the new product development process of third parties (Kasabov and Delbridge, 2008). McDonald-Junor (2015) finds a similar pattern evident in peripheral regions within the UK that are home to concentrations of bioscience related firms.

What emerges is a picture of a successful biotech incubator that formed the basis of an embryonic bioscience cluster in Nottingham - centred on but not limited to BioCity. Hence 
when BASF took the decision to sell Knoll Pharmaceuticals to Abbott Laboratories in 2000, all three of the streams in figure 2 converged. By so doing they created what was potentially a unique window of opportunity. Had the site become available ten years earlier or ten years later it is much less certain that local institutions would have had the capability or resources required to take advantage of the opportunity. Through these three co-evolving streams a new window of opportunity emerged alongside the institutional capability to take advantage of it.

\section{Similar path creation elsewhere?}

The case of Nottingham and the manner in which a new bioscience development path has been created in this way raises a number of important questions. For policymakers and those involved in economic development perhaps the crucial question is whether this model is place specific or is capable of wider replication?

Recent evidence indicates the latter, with clear signs that the Nottingham recipe is transferable and has been applied at other locations in the UK in what amount to similar situations. In each instance the trigger for the development of a bioscience incubator has been the departure (or significant down-sizing) of a major pharmaceutical company and the associated closure of a major research laboratory facility. Table 4 provides details of three notable examples, namely BioPark Herts developed at laboratories vacated by the Swiss pharmaceutical giant Roche, BioCity Scotland at Motherwell developed from laboratories vacated by the American pharmaceutical company Merck and BioHub Manchester utilizing the laboratories of the British pharmaceutical company Astra Zeneca. All three were triggered by the departure/closure of research facilities and like BioCity Nottingham comprise refurbished research laboratories rather than new build facilities as often found elsewhere. This should be no surprise given the character of the concentration, intensification of competition and the shift to 'open innovation' that marked the global pharmaceuticals sector in the opening decades of the twenty-first century. This was a global phenomenon that impacted on many firms and the localities in which they were based.

\footnotetext{
$* * * * * * * * * * * * * * * * * * * * * * * * * *$

Insert Table 4

$* * * * * * * * * * * * * * * * * * * * * * * * * *$
} 
The similarities go beyond the simple reuse of vacated laboratory space. In each case, we can observe the redundancy of a long established industrial facility. It is evident from these developments that many of the ingredients central to the Nottingham bioscience story are present in other localities. Furthermore, in the explicit use and acknowledgement of the BioCity Nottingham model, we see evidence of policy transference/learning between agencies and authorities in different UK localities. A local National Health Service (NHS) influence is significant in two of the four sites in question and economic development/enterprise agencies were significant players in three. Local authorities also played significant roles - particularly in the period after 2010 when the English RDAs were abolished.

Equally, it is possible to identify at least one example of a similar laboratory facility proving more problematic to re-task or re-use. The case of the former Astra Zeneca facility in Loughborough is instructive - not least because closure coincided almost exactly with the abolition of EMDA, one of the key institutional actors central to the development of BioCity (Mathiason 2010). Occurring a full decade after BioCity, but in the same region and in a town that is also home to a university with a relevant research profile, some but not all components of Nottingham's local recipe were present. At the time of writing, more than seven years after closure was announced, much of the site remains unused ${ }^{4}$.

\section{Concluding Discussion - of agency and agencies}

It is at the firm and the institutional levels that we start to see the emergence of a more place specific set of contingencies that, with the considerable benefit of hindsight, we can say led to the creation of a unique window of opportunity in Nottingham circa 2000/2001. It is here too that we see the evolution, in the interplay between firms, administrative and scientific institutions, of the capabilities necessary to take advantage of the opportunity. We also observe the emergence of specialised and localised markets for scientific labour and services of direct relevance to the kinds of biotech businesses attracted to Nottingham and BioCity after 2001.

Equally important is the role of agency - individual, corporate and institutional. From the gift of a fully equipped industrial laboratory and trial drug manufacturing facility by BASF - to key decisions by individuals, company boards and institutions, agency shaped both the problems faced by Nottingham (losing pharmaceuticals manufacture) and the availability of specific assets that could be redeployed to take advantage of a new local and global opportunity. 
Finally we note the key role played by a new institutional player on the ground in Nottingham, with both the remit and the resources to act as an enabler or in Kingdon's (1995), terminology 'a policy entrepreneur' able to couple the three different streams of our version of the MSF in order to establish a new development path in the city. A path that was rooted in Nottingham's history of industrial science and centred on the former Boots laboratory in Pennyfoot Street. Thus while Nottingham's recent development carries a strong flavour of path dependency, it is impossible to fashion a plausible explanation for the emergence of a bioscience related development path in recent years without acknowledging the important role fulfilled by both individual and institutional actors. Indeed, this may be the most noteworthy insight can be derived from this case for wider debates about the nature of path creation in post-industrial cities.

In the context of long term structural change to Nottingham's economy - the move away from manufactures towards services - the case of bioscience in Nottingham presents something of a conundrum for local policy makers. On the face of it, the emergence of a bioscience cluster conveys a message of hope in demonstrating that it is indeed possible for localities to adapt, applying the legacies of old manufacturing industry to new knowledge intensive opportunities. Considered from another perspective it also encapsulates the scale of the challenges inherent in these processes. The new bioscience cluster is a fraction of the size of clusters in the 'golden triangle', such as the biotechnology cluster at Cambridge and the mass employing pharmaceuticals manufacturing sector from which it has emerged. Hence Nottingham will need to foster more clusters in other sectors, if its economy as a whole is to attain the sunlit uplands of a positive post-industrial future. From where these will arise is by no means clear. 


\section{Endnotes}

${ }^{1}$ Alan Sillitoe's 1958 classic tale of industrial life in Nottingham.

${ }^{2}$ While pharmaceutical companies utilized features of Silicon Valley's industrial structure (i.e. the degree of vertical integration) highlighted by Saxenian (1996), they do not appear to have relied on features of the region's culture.

${ }^{3}$ The English Regional Development Agencies (RDAs) were created under Tony Blair's first Labour Government 1997-2001. The Regional Development Agencies Act 1998 established 8 regional development agencies in England that came into being in April 1999 (The London Development Agency followed a year later). Each RDA had a statutory remit to "(a) further the economic development and the regeneration of its area; (b) to promote business

efficiency, investment and competitiveness in its area, (c) to promote employment in its area, (d) to enhance the development and application of skills relevant to employment in its area, and (e) to contribute to the achievement of sustainable development in the United Kingdom where it is relevant to its area to do so."

${ }^{4}$ The latest initiative intended to kick start the process of regeneration on the site was its inclusion in a newly designated Enterprise Zone (Leicester and Leicestershire Enterprise Partnership 2017). 


\section{Acknowledgement}

The authors gratefully acknowledge the Economic and Social Research Council for funding (ESRC Award Reference: ES/H039716/1) part of the research upon which this paper is based through a CASE PhD studentship entitled 'From Property Management to Business Growth: Business Support in Biotech Incubators'. We also wish to thank Professor Anne Green and two anonymous reviewers for their constructive suggestions and encouragement in relation to the development of this paper. 


\section{References}

Abelhauser, W., von Hippel, W., Johnson, J.A. and Stokes, R.G. (2004) German Industry and Global Enterprise, BASF: the History of a Company, Cambridge: Cambridge University Press.

Amison, P. and Bailey, D. (2015) Phoenix industries and open innovation? The Midlands advanced automotive manufacturing and engineering industry, Cambridge Journal of the Regions, Economy and Society, 7: 397-411.

Beckett J. V., 1988. The East Midlands from A.D. 1000, London : Longman.

Boschma R.A. (2004) Competitiveness of regions from an evolutionary perspective, Regional Studies 38: 993-1006.

Bristow, G. and Healy, A. (2015) Crisis response, choice and resilience: insights from complexity thinking, Cambridge Journal of Regions Economy and Society, 8: 241-256.

Chapman, S.D. (1974). Jesse Boot of Boots the Chemists: A study in business history, London: Hodder and Stoughton.

Chapman, S.D. (2002). Hosiery and Knitwear: Four Centuries of Small Scale Industry in Britain, c.1584-2000, Oxford: Oxford University Press.

Chapman, S.D. (2006) Economy, industry and employment, in J.V. Beckett (ed.) A Centenary History of Nottingham, Chichester: Phillimore, 480-512.

Charles, D. and Wray, F. (2015) The English science cities: a new phase in science-based urban strategy, International Journal of Knowledge-Based Organizations. 5: 4-19.

Chesbrough, H.W. (2006) Open Innovation: The New Imperative for Creating Profit from Technology, Boston, MA: Harvard Business School Press,

Christopherson, S. (2009) Building "phoenix industries" in our old industrial cities, in J. Tomaney (ed.) The Future of Regional Policy, London: The Smith Institute, 78-86.

Collett, S. (2000) BASF and Knoll Pharmaceuticals Part One: Growth by Acquisition, Case 300-101-1, Cranfield : The Case Centre,

Coombes, M., Charles, D., Raybould, S. and Wymer, C. (2005) City Regions and Polycentricity: the East Midlands Urban Network, a report for the East Midlands Development Agency, Nottingham. Available at: http://irep.ntu.ac.uk/id/eprint/528/

Connon, H. (2003). Incubatorcity bids to hatch golden egg, The Observer, Business Section, $19^{\text {th }}$ October 2003. Available at:

https://www.theguardian.com/business/2003/oct/19/theobserver.observerbusiness2

[Accessed 4th May 2017]

Corley, T.A.B. (2003). The British pharmaceutical industry since 1851, in L. Richmond, J. Stevenson and A. Turton (eds.) The Pharmaceutical Industry: A Guide to Historical Records, Aldershot: Ashgate, 14-32.

Dawley, S. (2013) Creating new paths? Offshore wind, policy activism, and peripheral region development, Economic Geography, 90: 91-112. 
Dawley, S., MacKinnon, D., Cumbers, A. and Pike, A. (2015) Policy activism and regional path creation: the promotion of offshore wind in North East England and

Scotland. Cambridge Journal of Regions, Economy and Society, 8: 257-272.

DTI (1999) Biotechnology Clusters: report of a team led by Lord Sainsbury, Minister of Science, London: Department of Trade and Industry.

Doussard, M. and Schrock, G. (2015) Uneven decline: linking historical patterns and processes of industrial restructuring to future growth trajectories. Cambridge Journal of Regions, Economy and Society, 8: 149-165.

Ehret, M., McDonald-Junor, D. and Smith, D J. (2012) 'High technology and economic development: the BioCity Nottingham technology incubator', International Journal of Entrepreneurship and Innovation, 13: 301-309.

East Midlands Development Agency (2006) A flourishing region: Regional Economic Strategy for the East Midlands 2006-2020, Nottingham: East Midlands Development Agency.

Etzkowitz, H. (1993) Enterprises for science: the origins of science-based regional economic development, Minerva, 31: 326-360

Fornahl, D., Hassink, R., Klaerding, K., Mossig, I., Schröder, H. (2012) From the old path of ship-building onto the new path of wind energy? The case of northern Germany, European Planning Studies, 20: 835-855.

Green, D. (1994) BASF in $£ 850 \mathrm{~m}$ Deal to Acquire Boots, Financial Times, $15^{\text {th }}$ November 1994: 1,20 .

Hansard (2008) Memorandum submitted by Oxford Innovation Ltd, Hansard, $1^{\text {st }}$ October 2008. Available at: Source: http://www.parliament.the-stationeryoffice.co.uk/pa/cm200809/cmselect/cmberr/89/89we120.htm. [Accessed $18^{\text {th }}$ June 2015]

Heath, T. (2010) Nottingham: 'A consistent and integrated approach to urban design', in J. Punter (ed.) Urban Design and the British Urban Renaissance, Abingdon: Routledge, 148164.

Henstock,A. Dunster, S.and Wallwork, S. (2006), Decline and regeneration: Social and economic life, in J.V. Beckett (ed.) A Centenary History of Nottingham, Chichester: Phillimore, 132-164.

Hoskings, P. (1993) Manoplax: from heart to heartbreak, The Independent, $24^{\text {th }}$ July 1993. Available at: http://www.independent.co.uk/news/business/manoplax-from-heart-toheartbreak-with-millions-lost-on-its-wonder-drug-patrick-hosking-asks-whether1487095.html [Accessed $18^{\text {th }}$ June 2015]

John, G. and Reve, T. (1982) The reliability and validity of key informant data from dydadic relationships in marketing channels, Journal of Marketing Research, 19: 517-524.

Jones, O. (2000) Innovation Management as a Post-Modern Phenomenon: the Outsourcing of Pharmaceutical R \& D, British Journal of Management, 11: 341-356. 
Kasabov, E. and Delbridge, R., 2008. Innovation, embeddedness and policy: evidence from life sciences in three UK regions. Technology Analysis and Strategic Management, 20: 185200.

Kingdon, J.W. (1995) Agendas, Alternatives and Public Policies, New York: HarperCollins.

Lawton, C., Bickerton, C.G., and Thompson, P. (2014) Benchmarking Nottingham's Economy and Labour Market, Nottingham: Nottingham Business School and The Nottingham Post. Available at: http://irep.ntu.ac.uk/id/eprint/27438/ [Accessed on $2^{\text {nd }}$ May 2017].

Leicester and Leicestershire Enterprise Partnership (2017) Loughborough \& Leicester Enterprise Zone. Available from: https://www.llep.org.uk/enterprise-zone/our-enterprisezones/loughborough-leicester-ez/ [Accessed on $2^{\text {nd }}$ May 2017].

Marshall, A. (1920) Principles of Economics, $8^{\text {th }}$ edition, London: Macmillan.

Martin, R., (2005). Thinking about regional competitiveness-critical issues. Nottingham: East Midlands Development Agency.

Martin R. (2010) Roepke lecture in economic geography - rethinking regional path dependence: beyond lock-in to evolution, Economic Geography 86: 1-27.

Martin, R. (2012) Regional economic resilience, hysteresis and recessionary shocks. Journal of Economic Geography, 12: 1-32.

Martin, R. and Sunley, P. (2006) Path dependence and regional economic evolution, Journal Economic Geography 6: 395-437.

Mathiason, N. (2010) AstraZeneca to close UK research centre with 1,200 job losses, The Guardian, 2nd March 2010. Available at: https://www.theguardian.com/business/2010/mar/02/astrazeneca-close-uk-research-centre [Accessed $4^{\text {th }}$ May 2017]

Mathieson, S.A. (2011) England's NHS teaching hospitals: a capital affair, The Guardian, $29^{\text {th }}$ June 2011. Available at: https://www.theguardian.com/healthcarenetwork/2011/jun/29/england-nhs-teaching-hospitals-london-capital. [Accessed: 27th September 2016]

McDonald-Junor, D. (2015) From property management to business growth: Business support in UK biotechnology incubators, unpublished PhD thesis, Nottingham: Nottingham Trent University.

Neffke, F., Henning, M. and Boschma, R. (2011) How do regions diversify over time? Industry relatedness and the development of new growth paths in regions, Economic Geography, 87: 237-265.

Nelson, R.R. and Winter, S.G. (1982) An Evolutionary Theory of Economic Change, Cambridge, MA: Harvard University Press.

Nottingham City Council (2012) The Nottingham Growth Plan, Nottingham. 
Nottingham Post (2013) Experian continues to deliver jobs and growth, Nottingham Post $12^{\text {th }}$ February 2013. Available at: http://www.nottinghampost.com/Experian-continuers-deliverjobs-growth/story-18125776-detail/story.html [Accessed 20 ${ }^{\text {th }}$ March 2016]

Owen, G. (1999) From Empire to Europe: The Decline and Revival of British Industry since the Second World War, London: Harper Collins.

Pisano, G. P. (2006) The Business of Science: The Promise, The Reality and The Future of Biotech, Cambridge, MA: Harvard University Press,.

Pollard, S. (1992) The Development of the British Economy 1914-1990, $4^{\text {th }}$ edition, London: Edward Arnold.

Rosen, P. (2002) Framing Production: Technology, Culture and Change in the British Bicycle Industry, Cambridge, MA: MIT Press.

Rossiter, W. (2016) A tale of two cities: Rescaling economic strategy in the North Midlands, Local Economy, 31: 836-856.

Rossiter, W. and Price, L. (2013) Local economic development strategy under regional development agencies and local enterprise partnerships: applying the lessons of the multiple stream framework, Local Economy, 28: 852-867.

Rossiter, W. and Smith, D.J. (2017) Institutions, place leadership and public entrepreneurship: Reinterpreting the economic development of Nottingham, Local Economy, 32: 374-392.

Saxenian, A (1996) Regional Advantage: Culture and Competition in Silicon Valley and Route 128, Cambridge, MA: Harvard University Press.

Simmie, J. (2012) Path dependence and new technological path creation in the Danish wind power industry, European Planning Studies, 20: 753-772.

Slinn, J. (2008) Patents and the UK pharmaceutical industry between 1945 and the 1970s', History and Technology, 24: 191-205.

Smith, D. J. and Ehret, M. (2013): 'Beyond the golden triangle': Biotechnology incubation in the East Midlands region of the UK. Local Economy, 28: 66-84.

Swords, J. (2013) Michael Porter's cluster theory as a local and regional development tool: The rise and fall of cluster policy in the UK, Local Economy, 28: 369-383.

THE (2001), £4m gift for innovation centre, Times Higher Education, $31^{\text {st }}$ August 2001. Available at: https://www.timeshighereducation.com/news/4m-gift-for-innovationcentre/164624.article [Accessed: 18thJune 2015]

Wells, F.A. (1966) Industrial Structure, in K.C. Edwards (ed.) Nottingham and Its Region, Nottingham: British Association for the Advancement of Science, 405- 415.

Zahariadis, N. (2007) The multiple streams framework: structure, limitations, prospects, in P.A. Sabatier (ed.) Theories of the Policy Process, $2^{\text {nd }}$ edition, Cambridge, MA: West View Press, 65-92. 
Table 1

UK-owned Pharmaceutical companies, 1982

\begin{tabular}{c|l|c|c|c}
$\begin{array}{l}\text { UK } \\
\text { Ranking }\end{array}$ & Company & $\begin{array}{l}\text { Pharmaceutical } \\
\text { sales }(£ m)\end{array}$ & $\begin{array}{c}\text { Pharmaceuticals } \\
\text { \% Total sales }\end{array}$ & $\begin{array}{l}\text { World } \\
\text { ranking }\end{array}$ \\
\hline 1. & Glaxo & 990.0 & $88.0 \%$ & $18 \mathrm{th}$ \\
2. & ICI & 839.0 & $7.0 \%$ & $23 \mathrm{rd}$ \\
3. & Wellcome & 837.0 & $80.0 \%$ & $24 \mathrm{th}$ \\
4. & Beacham & 782.0 & $31.3 \%$ & $25 \mathrm{th}$ \\
5. & Boots & 399.0 & $16.0 \%$ & 42nd \\
6. & Fisons & 206.0 & $36.0 \%$ & 66th
\end{tabular}

Source: Owen (1999) 
Table 2

Mergers and acquisitions in pharmaceuticals, 1989-2000

\begin{tabular}{|l|l|l|}
\hline Year & Companies & Countries \\
\hline 1989 & Dow/Marion & US/US \\
\hline & Bristol-Myers/Squibb & US/US \\
\hline & SmithKline/Beecham & US/UK \\
\hline 1990 & Rhône-Poulenc/Rorer & France/US \\
\hline & Roche/Genentech & Switzerland/US \\
\hline & SmithKline Beecham/Sterling Health & UK/US \\
\hline & BASF/Boots & Germany/UK \\
\hline & American Home Products/ American Cynamid & US/US \\
\hline & El Sanofi/Sterling Drug & France/US \\
\hline 1994 & Roche/Syntex & Switzerland/US \\
\hline & Glaxo/Wellcome & UK/UK \\
\hline & Hoescht/Marion Merrell Dow & Germany/US \\
\hline & Pharmacia/Upjohn & Sweden/US \\
\hline 1996 & Rhône-Poulenc/Fisons & France/UK \\
\hline 1997 & Roche/Boehringer & Switzerland/Switzerland \\
\hline 1999 & Hoescht/ Rhône-Poulenc & Switzerland/Germany \\
\hline & Astra/Zeneca & Germany/France \\
\hline 2000 & Glaxo Wellcome/SmithKline Beecham & Sweden/UK \\
\hline & Pfizer/Warner-Lambert & UK/UK \\
\hline
\end{tabular}

Source: Owen (1999) 
Table 3

Chronology of Manoplax development

\begin{tabular}{|l|l|l|}
\hline Year & Month & Action \\
\hline 1979 & July & Synthesis of BTS49465 \\
\hline 1980 & March & Animal tests start \\
\hline 1982 & September & Tested on volunteers \\
\hline 1983 & October & Clinical trial certificate \\
\hline 1983 & November & Used in heart failures \\
\hline 1984 & December & Approval inquiry starts \\
\hline 1985 & May & UK Phase 2 dosage trials \\
\hline 1990 & July & Phase 3 safety trials \\
\hline 1991 & October & US heart panel approval \\
\hline 1992 & August & License granted in UK \\
\hline 1992 & September & Sent to UK doctors \\
\hline 1992 & December & Licence granted in USA \\
\hline 1993 & March & Launched in USA \\
\hline 1993 & April & Warning on dosages \\
\hline 1993 & July & Manoplax withdrawn \\
\hline
\end{tabular}

Source: Hoskings (1993) 
Table 4:

Evidence of similar developments in other localities

\begin{tabular}{|l|l|l|l|l|}
\hline Incubator & $\begin{array}{l}\text { BioCity } \\
\text { Nottingham }\end{array}$ & BioPark Herts & $\begin{array}{l}\text { BioCity } \\
\text { Scotland }\end{array}$ & $\begin{array}{l}\text { BioHub } \\
\text { Manchester }\end{array}$ \\
\hline Location & Nottingham & Welwyn & Motherwell & Alderley Edge \\
\hline Parent firm & $\begin{array}{l}\text { BASF } \\
\text { Boots })\end{array}$ & Roche & Merck & AstraZeneca \\
\hline $\begin{array}{l}\text { Source } \\
\text { Industry }\end{array}$ & Pharmaceuticals & Pharmaceuticals & Pharmaceuticals & Pharmaceuticals \\
\hline $\begin{array}{l}\text { Date est'd } \\
\text { institutional } \\
\text { facilitators }\end{array}$ & 2003 & 2006 & 2011 & 2013 \\
\hline $\begin{array}{l}\text { Development } \\
\text { agency }\end{array}$ & EMDA & SEEDA & $\begin{array}{l}\text { Scottish } \\
\text { Enterprise }\end{array}$ & n/a \\
\hline $\begin{array}{l}\text { Local authority } \\
\text { Nottingham City }\end{array}$ & $\begin{array}{l}\text { Welwyn } \\
\text { Hatfield } \\
\text { Borough } \\
\text { Council }\end{array}$ & $\begin{array}{l}\text { North } \\
\text { Lanarkshire } \\
\text { Council }\end{array}$ & $\begin{array}{l}\text { Cheshire } \\
\text { Council }\end{array}$ \\
\hline $\begin{array}{l}\text { NHS } \\
\text { University }\end{array}$ & $\begin{array}{l}\text { Nottingham } \\
\text { University/NTU } \\
\text { University }\end{array}$ & $\begin{array}{l}\text { Various } \\
\text { Glasgow } \\
\text { Edinburgh } \\
\text { and }\end{array}$ & $\begin{array}{l}\text { Manchester } \\
\text { University }\end{array}$ \\
\hline
\end{tabular}


Figure 1: Towards an alternative path dependence model of local industrial evolution

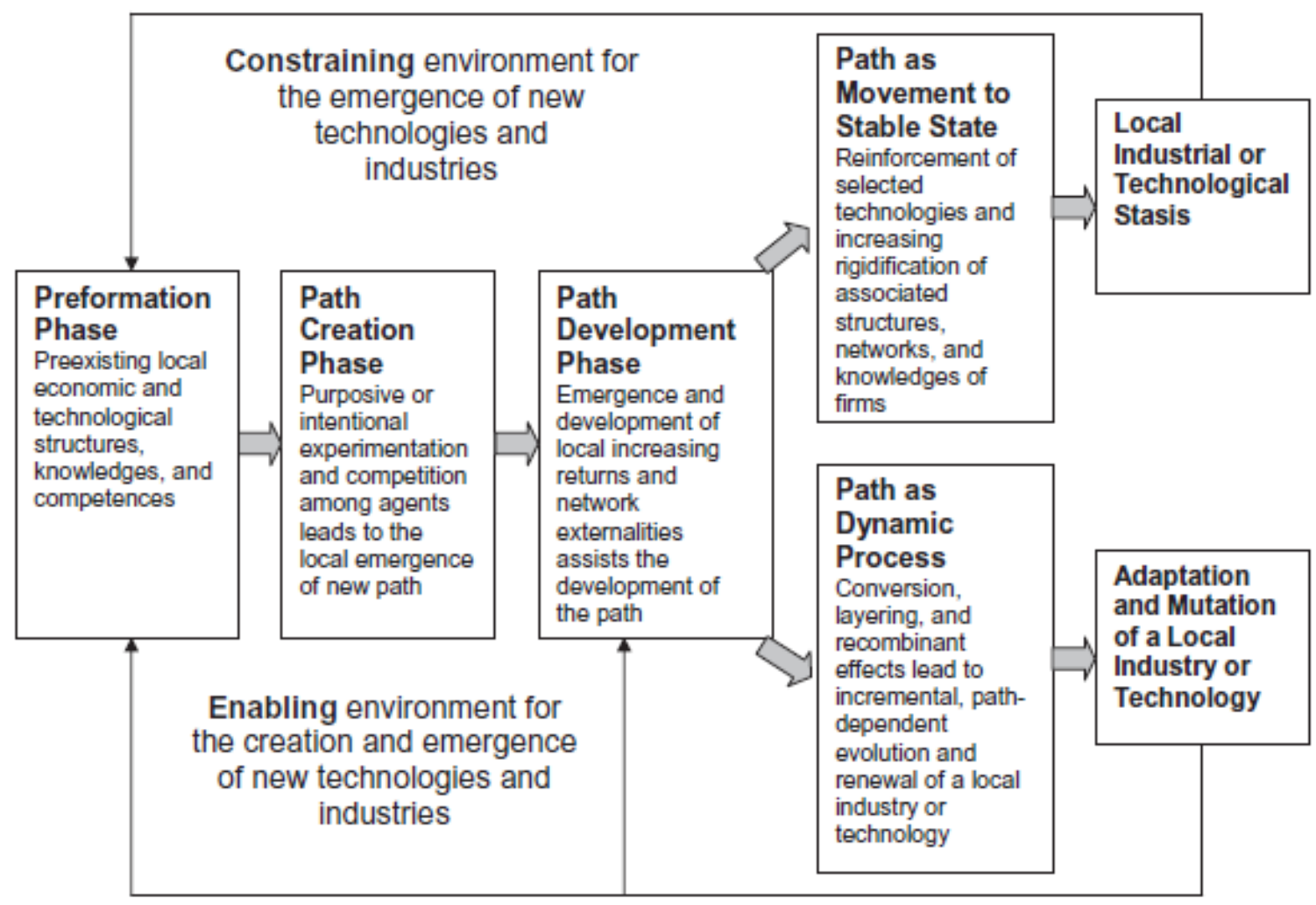

Source: (Martin 2010, 21)

Figure 2 Simplified model of path creation loosely based on MSF

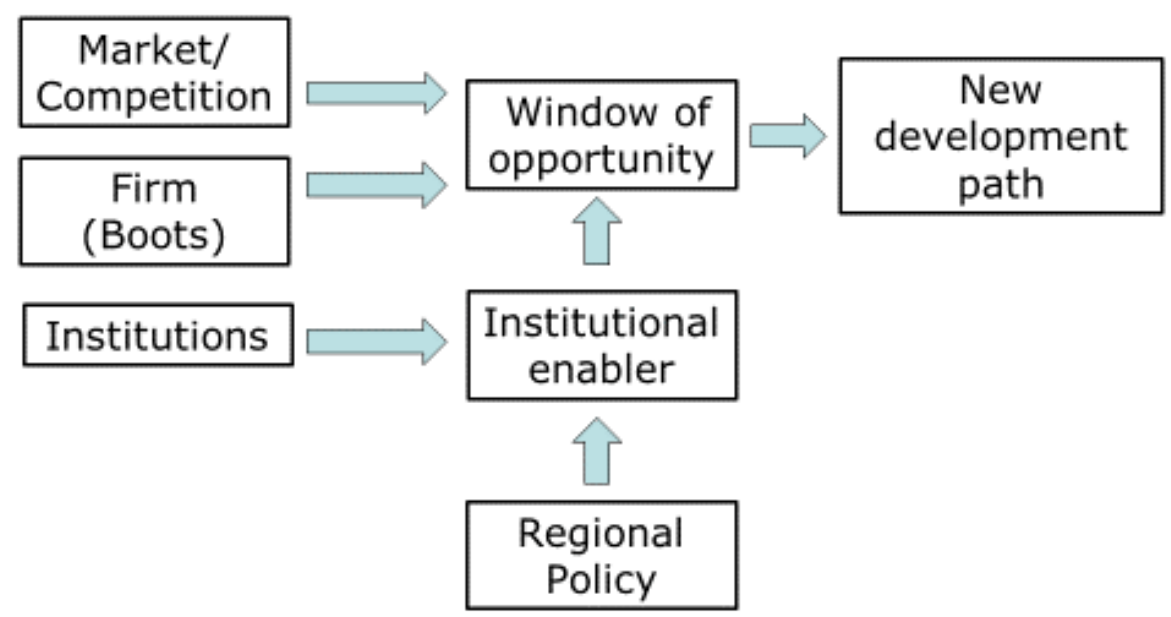

